\title{
A INCONSTITUCIONALIDADE DO DECRETO 64.074: A PROIBIÇÃO DO USO DE MÁSCARAS
}

Lucas Catib de Laurentiis* Alice Maldonade Bryan ${ }^{* *}$

Resumo: Este trabalho teve como objetivo analisar a constitucionalidade do Decreto 64.074 de 2019 elaborado pelo Governador do Estado de São Paulo em que se proíbe o uso de máscaras durante as manifestações realizadas neste estado, sob a ótica do Direito Constitucional Brasileiro em comparação com o Direito Constitucional Alemão. Para isso, também foi analisada uma decisão do Tribunal Constitucional Alemão sobre a liberdade de reunião. O método utilizado na pesquisa foi o analítico e dogmático. Por fim, estabeleceramse os limites para o direito de manifestar-se livremente, direito fundamental previsto no artigo $5^{\circ}$, inciso XVI da Constituição Federal brasileira.

Palavras-chave: Direito Constitucional; Liberdade de Reunião; Direitos Fundamentais; Direitos Humanos e Políticas Públicas.

\section{THE INCONSTITUTIONALITY OF THE DECREE N$^{\circ}$ 64.074: THE MASK PROHIBITION}

\begin{abstract}
This work aimed to analyze the constitutionality of Decree 64.074/2019 prepared by the Governor of the State of São Paulo, which prohibits the use of masks during demonstrations held in this state, from the perspective of Brazilian Constitutional Law in comparison with German Constitutional Law. To this end, a decision by the German Constitutional Court on freedom of assembly was analyzed. The method used in this research was analytical and dogmatic. Finally, it was intended to establish limits for the right to
\end{abstract}

\footnotetext{
* Mestre e Doutor em Direito pela Universidade de São Paulo. Professor e Coordenador do PPGD da PUC de Campinas. E-mail: lucas.laurentiis@ @uc-campinas.edu.br

${ }^{* *}$ Mestranda do PPGD da PUC de Campinas. E-mail: alice.mb1 @ puc-campinas.edu.br
} 
manifest freely, a fundamental right provided in Article 5, item XVI of the Brazilian Federal Constitution.

Keywords: Constitutional Law; Freedom of Assembly; Fundamental rights; Human Rights and Public Policies.

\section{INTRODUÇÃO}

Nesta pesquisa buscamos analisar os limites da liberdade de reunião sob a perspectiva do Direito Constitucional brasileiro e alemão. Para isso, serão analisados dois casos concretos através do método comparativo. O primeiro refere-se a uma decisão do Tribunal Constitucional alemão, que trata do direito de manifestação durante a pandemia do SARS-COV-19. O segundo caso analisado será o Decreto 64.074 de 2019 do Governador do Estado de São Paulo, que pró́be o uso de máscaras durante as manifestações realizadas no estado de São Paulo.

Além disso, sob a ótica da determinação dogmática de conceitos, o artigo conta com fontes do direito constitucional alemão, tendo em vista que neste país existem estudos avançados sobre o tema, que é resultado de um contexto histórico-social enfrentado pela Alemanha. Ademais, serão utilizados textos científicos do Direito Constitucional brasileiro para que seja possível a análise da constitucionalidade do Decreto Estadual de São Paulo.

É importante ressaltar que este tema não é amplamente discutido dentro do direito brasileiro, como é revelado na jurisprudência do Supremo Tribunal Federal, tendo ele sido abordado pouquíssimas vezes, após a promulgação da Constituição Federal brasileira de 1988. Atualmente, pela primeira vez, a matéria está na Corte (ARE 905149), com repercussão geral reconhecida, para ser julgada nos próximos anos. Apesar disso, desde 2013 inúmeras manifestações são realizadas pelo Brasil com pautas diversas. Diante disso, é de suma importância a discussão sobre os limites da liberdade de reunião que enfrentam questões de como podem ser realizadas as manifestações e onde elas podem ser feitas. Portanto, este artigo tem como objetivo final responder essas questões para promover a efetiva concretização deste direito. 


\section{OBJETIVOS}

A pesquisa teve como objetivo analisar a constitucionalidade do Decreto 64.074 de 2019 elaborado pelo Governador do Estado de São Paulo em que se proíbe o uso de máscaras durante as manifestações realizadas neste estado, sob a ótica do Direito Constitucional Brasileiro em comparação com o Direito Constitucional Alemão. Para isso, também foi analisada uma decisão do Tribunal Constitucional Alemão sobre a liberdade de reunião. Por fim, pretendeu-se estabelecer limites para o direito de manifestar-se livremente, direito fundamental previsto no artigo $5^{\circ}$, inciso XVI da Constituição Federal brasileira.

\section{METODOLOGIA}

A pesquisa se insere no campo da dogmática constitucional, buscando identificar padrões decisórios e características do direito fundamental abordado. Foram analisados artigos referentes aos limites da liberdade de reunião no direito brasileiro, assim como artigos alemães sobre este mesmo tema. Por isso, o método da pesquisa pode ser definido como analítico e dogmático.

\section{DECISÃO DO TRIBUNAL CONSTITUCIONAL ALEMÃO}

Em dezembro de 2019 foi descoberto na cidade de Wuhan na China um novo vírus com alta possibilidade de contaminação e até de letalidade, o SARS-COV-19 (Coronavírus) $^{1}$. Por conta disso, todo o território chinês ficou em isolamento, com suas fronteiras fechadas.

Logo, em poucos meses, o novo vírus chegou a outros países, tornando-se uma pandemia. Estes países se viram na necessidade de também impor medidas de isolamento social, total ou parcial, para que fosse possível o enfrentamento do vírus, pelo fato de que na época ainda não havia vacina e estudos científicos apontavam que o isolamento era a única forma de conter a rápida contaminação. Nesta situação, os cidadãos só tinham permissão de

\footnotetext{
${ }^{1}$ Coronavírus na China: o que se sabe sobre a misteriosa doença após confirmação de transmissão entre humanos. Em 20 de janeiro de 2020 Wuhan era epicentro da doença no mundo e alguns países da região já possuíam casos de contaminação com o vírus. Link: https://www.bbc.com/portuguese/internacional$\underline{\mathbf{5 1 1 5 7 4 8 7}}$
} 
sair de suas casas para atividades essenciais, como por exemplo, ir ao supermercado ou farmácia.

Na Alemanha não foi diferente, em meados de março de 2020 foi imposto o isolamento em todo o território alemão. As escolas, universidades, locais públicos e o comércio foram fechados a fim de diminuir a propagação do vírus. Dessa forma, grande parte da população ficou em suas casas por aproximadamente dois meses.

No entanto, um grupo de pessoas não aprovou a forma como estavam sendo adotadas as medidas de segurança na Alemanha e organizaram manifestações para reivindicar mudanças nessas condutas.

Em Giessen, cidade da região central da Alemanha, foram organizadas manifestações para os dias 14, 15, 16 e 17 de abril de 2020 das 14 horas até 18 horas, cujo título era "Fortalecimento da saúde ao invés de enfraquecimento dos direitos fundamentais proteção contra vírus, não contra pessoas". Os organizadores informaram à Prefeitura que o número de manifestantes foi reduzido para 30 com observância de todas as medidas de segurança, como o uso obrigatório de máscaras e distanciamento entre os manifestantes de pelo menos um metro e meio.

Porém, a Prefeitura não autorizou a realização das manifestações com base no Decreto Estadual de Hessen, que proibia a aglomeração de duas ou mais pessoas que não residiam na mesma casa. Ademais, foi argumentado que os organizadores não poderiam garantir que os manifestantes respeitariam a distância mínima e haveria risco de segurança pública e ordem pública.

Diante disso, os organizadores pleitearam uma ação judicial em face da Prefeitura de Giessen perante o juízo administrativo competente. Em sentença foi negado o pedido dos organizadores para a realização da manifestação, também com base no Decreto Estadual. Então, foi interposto um recurso pelos organizadores perante o Verwaltungsgerichtshof de Hessen (equivalente à segunda instância administrativa), que confirmou a sentença de primeira instância ${ }^{2}$.

Por conta disso, os autores da ação propuseram uma queixa constitucional com pedido liminar perante o Tribunal Constitucional argumentando que o seu direito fundamental

2 Notícia publicada sobre a decisão de segunda instância em proibir a realização de manifestação em Giessen no site oficial do Tribunal Administrativo de Hessen. https://verwaltungsgerichtsbarkeit.hessen.de/pressemitteilungen/versammlung-gie\%c3\%9fen-zumthema-\%e2\%80\%9egesundheit-st\%c3\%a4rken-statt-grundrechte-schw\%c3\%a4chen-\%e2\%80\%93 
de reunião, previsto no artigo $8^{\circ}$ da Lei Fundamental alemã (Grundgesetz) ${ }^{3}$ havia sido violado pela Prefeitura de Giessen.

O Tribunal Constitucional Alemão julgou procedente o pedido na queixa constitucional e reconheceu a violação do direito fundamental de reunião dos manifestantes na restrição feita pela Prefeitura.

$\mathrm{Na}$ decisão ${ }^{4}$ foi reconhecido o direito fundamental de todos os alemães se reunirem pacificamente e sem armas, sem registro ou permissão, previsto no artigo $8^{\circ}$ da Lei Fundamental. Conforme o parágrafo segundo desse artigo, é possível que tal direito seja restringido para reuniões realizadas ao ar livre com base em lei. Segundo o juízo, na ordem de proibição a conduta proibida foi descrita como "realização de uma reunião pública", o que leva a questionar se isso significa uma proibição total das reuniões, inclusive as que são integradas por duas pessoas que residem juntas, ou se essa expressão se aplica somente às manifestações que causem alguma forma de risco à saúde pública.

Além disso, no Decreto Estadual de Hessen (Verordnung zur Bekämpfung des Corona-Virus) não havia nenhuma proibição geral expressa de aglomerações de mais de duas pessoas. Está disposto que o contato entre pessoas que não vivem na mesma casa deve ser limitado para o mínimo possível. Também, ao restringir as manifestações a Prefeitura não levou em consideração todas as circunstâncias do caso concreto.

Dessa forma, o Tribunal Constitucional Alemão concedeu a liminar para que fosse possível a realização das manifestações, com fulcro na Lei Fundamental, que não foi respeitada pela Prefeitura de Giessen, bem como a Lei de Assembleias (VersammlG), que regulamenta as hipóteses em que uma manifestação pode ser restringida. Para o Tribunal, as reuniões organizadas não contrariavam as leis infraconstitucionais, uma vez que todas as medidas sanitárias para evitar o contágio do vírus seriam respeitadas.

Com essa decisão, o Tribunal Constitucional Alemão ordenou que a Prefeitura de Giessen revisse suas proibições. Assim sendo, a Prefeitura permitiu a realização das manifestações, o que era o mais coerente a ser feito, uma vez que o Tribunal considerou essas reuniões protegidas constitucionalmente.

3 Artikel 8 (1) Alle Deutschen haben das Recht, sich ohne Anmeldung oder Erlaubnis friedlich und ohne Waffen zu versammeln. (2) Für Versammlungen unter freiem Himmel kann dieses Recht durch Gesetz oder auf Grund eines Gesetzes beschränkt werden.

Tradução livre: Artigo 8 (1) Todos os alemães têm o direito de se reunir pacificamente e sem armas, sem registro ou permissão. (2) Para reuniões ao ar livre, esse direito pode ser limitado por lei.

${ }^{4}$ BVerfGE, 828/20, p. 3. 


\section{ANÁLISE DA DECISÃO DO TRIBUNAL CONSTITUCIONAL ALEMÃO}

Durante a pandemia do Coronavírus (COVID-19) diversas manifestações foram realizadas ao redor do mundo, algumas com reinvindicações parecidas com a organizada em Giessen e outras com pautas diferentes, como as que ocorreram por todos os Estados Unidos da América após a morte brutal de um jovem negro, George Floyd ${ }^{5}$.

Portanto, o debate sobre quais são as limitações do direito de manifestar-se livremente durante uma pandemia de um vírus altamente contagioso foi realizado por autoridades de vários países. O Tribunal Constitucional Alemão foi um dos primeiros tribunais do mundo a se posicionar sobre este tema e trouxe elementos importantes para essa discussão. Desta forma, passaremos à análise dessa decisão sob a perspectiva do direito constitucional alemão com base em textos científicos sobre o tema.

Conforme já abordado, o artigo $8^{\circ}$ da Lei Fundamental alemã (Grundgesetz) dispõe que todos os alemães têm direito de se reunir pacificamente, sem armas, sem registro ou permissão. Este artigo restringe a titularidade desse direito somente para os alemães, diferentemente de como está previsto na Constituição Federal brasileira que determina que "todos" têm o direito de se reunir pacificamente. No entanto, no artigo de Kniesel e Poscher (2004, p. 422) este direito é definido como encontro de várias pessoas para uma discussão em comum com o objetivo de participar na formação da opinião pública.

Nesta definição é possível identificar uma particularidade na proteção do direito de reunião na Alemanha: somente são protegidas as reuniões que visam um objetivo em comum e contribuam para a opinião pública. Dessa forma, torcidas de futebol e encontros musicais não estão protegidos constitucionalmente pelo direito de reunião, uma vez que esses tipos de reunião não têm como objetivo discutir algum assunto que forme uma opinião pública e não possuem um elemento comum que une a ação dos participantes ${ }^{6}$. Portanto, pode-se afirmar que na Alemanha rege uma democracia participativa e nem todas as reuniões

5 Morte de George Floyd: a pergunta simples com que uma professora pôs em evidência o racismo nos EUA. Nesta notícia do dia 7 de junho de 2020 é abordado o tema do racismo, que foi pauta de manifestações realizadas em mais de 75 cidades dos Estados Unidos. https://www.bbc.com/portuguese/internacional52913939

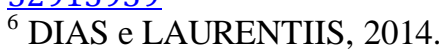


contribuem para o desenvolvimento desta, embora existam críticas sobre este tipo de limitação ${ }^{7}$.

No caso em tela, esta limitação não seria aplicada, tendo em vista que ao ser debatido as medidas de enfrentamento do Coronavírus no país, o tema se mostraria de extrema importância para o debate público possibilitando a formação da opinião pública.

Além disso, no texto constitucional alemão existe uma limitação quanto à forma que as manifestações devem ser realizadas, isto é: pacificamente e sem armas. Existe um consenso na doutrina alemã de que o termo "pacífico" não pode ser tão amplificado a ponto de excluir a possibilidade de realização da reunião. Nesse sentido, o uso de objetos para bloquear o acesso às ruas não é considerado como ato não pacífico ${ }^{8}$.

Diante disso, surgem questões em relação às manifestações que não têm violência física, mas sim simbólica, como por exemplo, as organizadas por grupos neonazistas. A jurisprudência alemã entendeu através da Lei de Assembleia, que este tipo de manifestações não traz benefícios para a formação da opinião pública, pelo contrário, elas prejudicam o debate democrático ${ }^{9}$.

No entanto, os autores Poscher e Kniesel discordam dessa posição, pois para eles manifestações e ideais extremistas não devem ser excluídas do debate democrático. Esta visão de democracia se mostra como ingênua e idealista. Na Democracia devem ser aceitos os defeitos e desvios de pensamentos que possam surgir, não somente aceitar as diferenças.

Com base nesses pressupostos, é possível afirmar que as manifestações organizadas na cidade de Giessen estão constitucionalmente protegidas, uma vez que respeitaram todos os preceitos trazidos pela Lei Fundamental. Todavia, por estas reuniões terem sido organizadas durante uma pandemia surgiram debates quanto ao conflito entre dois direitos fundamentais: o da liberdade de reunião e o direito à saúde.

Para solucionar casos de colisão entre direitos fundamentais, o autor alemão Robert Alexy, em seu livro a Teoria dos Direitos Fundamentais ${ }^{10}$, propõe a aplicação da proporcionalidade, que foi elaborada pelo Tribunal Constitucional Alemão e aplicada pela primeira vez no Caso Lüth ${ }^{11}$. Mas para aplicar esta técnica é necessário primeiramente

\footnotetext{
${ }^{7}$ KNIESEL E POSCHER, 2004.

${ }^{8}$ DIAS E LAURENTIIS, 2014.

${ }^{9}$ DIAS e LAURENTIIS, 2014, p. 660.

${ }^{10}$ ALEXY, 2014.

${ }^{11}$ Sobre este caso, o explica: Erich Lüth fazia parte do grupo de imprensa na cidade de Hamburg e propôs boicote aos filmes de Van Harlan, um diretor de cinema nazista, produzidos depois do final da Segunda Guerra
} 
abordar o motivo da existência da colisão entre direitos fundamentais. Isto pode ocorrer, pois o texto constitucional protege dois valores que possuem contradição concreta e ambos são princípios, ou seja, tem uma maior amplitude de aplicação, de forma que a solução deste conflito se torna difícil na medida em que ambos possuem a mesma hierarquia normativa ${ }^{12}$.

Por isso, a proporcionalidade consiste na aplicação de três elementos sucessivamente para que seja analisada a medida estatal que proibiu a concretização de um direito fundamental sob a justificativa de proteger outro direito fundamental. Os elementos são: a adequação, a necessidade e a proporcionalidade (em sentido estrito).

$\mathrm{Na}$ adequação, observa-se se o ato estatal é o meio mais adequado para alcançar o resultado ou objetivo pretendido. Nesta modalidade há um exame absoluto do ato. O segundo elemento é o da necessidade. Neste momento, será verificado se o ato estatal que limitou o direito fundamental é a alternativa menos restritiva possível para que o objetivo perseguido seja alcançado na mesma intensidade. Ou seja, questiona-se nesta etapa do teste se existe outro ato que limite menos o direito fundamental não fomentará o mesmo resultado. Uma vez que esse ato seja identificado o meio menos restritivo, a medida estatal se torna inválida.

O último elemento é o da proporcionalidade em sentido estrito. Este consiste no sopesamento entre a intensidade da restrição do direito fundamental atingido e a relevância da aplicação do direito fundamental que colide com o primeiro. Neste sentido, será examinado se os motivos que fundamentam a adoção do ato estatal têm peso suficiente para justificar a restrição do direito fundamental atingido.

Posto isto, passaremos para a aplicação da proporcionalidade no ato estatal da Prefeitura de Giessen, que proibiu a realização de manifestações na cidade por conta da pandemia do coronavírus. Primeiramente, ao analisar o elemento da adequação do ato da Prefeitura, pode-se afirmar que o ato estatal é adequado para alcançar o resultado, pois o objetivo central é evitar a contaminação de pessoas pelo vírus. Ao não permitir a realização da reunião este objetivo será alcançado, uma vez que não haverá riscos de contaminação.

Mundial. Lüth foi condenado pelo Tribunal de Hamburgo a não se pronunciar quanto às novas propostas de boicote, além do pagamento de multa pecuniária. Dessa forma, Lüth recorreu à Corte Constituional Alemã que, fez o sopesamento dos direitos fundamentais envolvidos no caso e considerou a incitação ao boicote de Lüth protegida pela liberdade de expressão garantida Lei Fundamental Alemã. Portanto, Lüth foi vencedor neste processo. (CARDOSO, 2016, p. 9-10)

${ }^{12}$ Explicitamente nessa linha: "os direitos colidem porque não estão dados de uma vez por todas; não se esgotam no plano da interpretação in abstrato. As normas de direito fundamental se mostram abertas e móveis quando de sua realização ou concretização na vida social. Daí a ocorrência de colisões. Onde há um catálogo de direitos fundamentais constitucionalizados, há colisões in concreto.” (STEINMETZ, 2001 p. 63) 
Dessa forma, verificaremos o próximo elemento que é o da necessidade. Através dele conseguimos observar que o ato da Prefeitura de Giessen não era a única alternativa para que o objetivo - não contaminação pelo vírus - fosse alcançado. Isso se deve pela possibilidade de os manifestantes realizarem a reunião respeitando as medidas de segurança sanitária, ou seja, manter o distanciamento mínimo de um metro e meio, uso de máscaras, álcool em gel e o número reduzido de participantes. Portanto, existe uma medida alternativa do ato emanado da Prefeitura de Giessen, que limitaria de forma menos intensa a liberdade de reunião e, ainda assim, asseguraria o direito à saúde de todos ao reduzir a possibilidade de contágio do coronavírus.

Deste modo, a decisão do Tribunal Constitucional alemão nos parece acertada ao permitir a realização das manifestações durante a pandemia do SARS-COV-19, pois a proibição se mostra como uma medida extrema, uma vez que existem formas de se assegurar a liberdade de reunião e, ao mesmo tempo, de adotar medidas de prevenção do contágio.

\section{DECRETO 64.074 DE 2019 ESTADO DE SÃO PAULO}

Em 18 de janeiro de 2019, o recém-eleito Governador do estado de São Paulo, João Dória, publicou o Decreto 64.074 que restringe o uso de máscaras ou qualquer outro tipo de paramento que oculte o rosto dos participantes em todo o território do estado.

Este decreto regulamenta a Lei 15.556 de 2014, promulgada pelo o então Governador do estado de São Paulo, Geraldo Alckimin, que também restringe o uso de máscaras ou qualquer paramento, que oculte o rosto da pessoa em manifestações e reuniões ${ }^{13}$.

${ }^{13}$ O GOVERNADOR DO ESTADO DE SÃO PAULO:

Faço saber que a Assembleia Legislativa decreta e eu promulgo a seguinte lei:

Artigo $1^{\circ}$ - O Estado garantirá, nos termos dos incisos IV e XVI do artigo $5^{\circ}$ da Constituição Federal, a qualquer pessoa o direito à manifestação do pensamento, sendo vedado o anonimato, e a reunir-se pacificamente, sem armas, em locais abertos ao público, independentemente de autorização, desde que não frustrem outra reunião anteriormente convocada para o mesmo local, sendo apenas exigido prévio aviso à autoridade competente, na forma desta lei.

Artigo $2^{\circ}$ - Na manifestação e reunião a que se refere o artigo $1^{\circ}$, com o objetivo de assegurar que ninguém a faça no anonimato, fica proibido o uso de máscara ou qualquer outro paramento que possa ocultar o rosto da pessoa, ou que dificulte ou impeça a sua identificação.

Parágrafo único - A proibição a que se refere o "caput" deste artigo não se aplica às manifestações e reuniões culturais incluídas no Calendário Oficial do Estado.

Artigo $3^{\circ}$ - À proibição constitucional de portar armas nas manifestações e reuniões públicas, incluem-se as de fogo, as armas brancas, objetos pontiagudos, tacos, bastões, pedras, armamentos que contenham artefatos explosivos e outros que possam lesionar pessoas e danificar patrimônio público ou particular. 
Além disso, logo em seu artigo primeiro, o Decreto estabelece que é necessária a comunicação prévia para o exercício do direito de reunião. Isto deve ocorrer nas reuniões que têm como objetivo a participação de mais de 300 manifestantes, sendo que a comunicação deverá ser feita para as autoridades da Polícia Militar e da Polícia Civil, através de um formulário preenchido pelos organizadores. Neste formulário, existe um ponto em que os organizadores devem afirmar que têm ciência da proibição ao anonimato e, portanto, do uso de máscaras "ou qualquer outro paramento que possa ocultar o rosto da pessoa, ou que dificulte ou impeça a sua identificação durante o evento".

Ademais, neste formulário existe outro ponto para que os organizadores declarem ciência da proibição constitucional de portar armas incluídas: "armas de fogo, as armas brancas, objetos pontiagudos, tacos, bastões, pedras, armamentos que contenham artefatos explosivos e outros instrumentos que possam lesionar pessoas e danificar patrimônio público ou particular".

Logo em seguida, o artigo $5^{\circ}$ deste decreto autoriza as Polícias Civil e Militar intervir nos casos em que os manifestantes usarem máscaras durante as manifestações. Nesse sentido, o Decreto prevê que a recusa do indivíduo poderá ser caracterizada como delito de desobediência disposto no artigo 330 do Código Penal e a pessoa poderá ser levada à Delegacia de Polícia para que seja feita a sua identificação. Além disso, caso o manifestante não porte documento de identificação, poderá ser conduzido à Delegacia para que seja feita a identificação criminal. Nesta última hipótese, o policial está autorizado a, eventualmente, contatar um familiar, responsável e até com seu empregador, podendo solicitar o seu comparecimento na Delegacia para apresentar identificação válida.

Dessa forma, este Decreto teve como objetivo regulamentar as formas como devem ser feitas as manifestações no território paulista, que prevê inclusive limitações para o direito de reunião, criticadas por parte da população ${ }^{14}$. Diante disso, passaremos para a análise deste dispositivo à luz do direito constitucional brasileiro.

Artigo $4^{\circ}$ - As manifestações e reuniões em locais e vias públicas, inclusive organizadas através das redes sociais, na Internet, conforme previsão constitucional, deverão ser previamente comunicadas às Polícias Civil e Militar, na forma de regulamento expedido pela Secretaria da Segurança Pública.

Artigo $5^{\circ}$ - Para a preservação da ordem pública e social, da integridade física e moral do cidadão, do patrimônio público e particular, bem como para a fiel observância do cumprimento desta lei, as Polícias Civil e Militar efetuarão as devidas intervenções legais.

Artigo $6^{\circ}$ - Esta lei deverá ser regulamentada até 180 (cento e oitenta) dias após a sua publicação.

Artigo $7^{\circ}$ - Esta lei entra em vigor na data de sua publicação.

${ }^{14}$ Bancada Ativista na Alesp denuncia na OEA ação da PM e decreto de Doria que regulamenta protestos. Membros da Assembleia Legislativa do Estado de São Paulo denunciaram o Decreto 64.074 na Organização dos 


\section{LIMITES DA LIBERDADE DE REUNIÃO}

O Decreto 64.074 do Governador do Estado de São Paulo não foi o primeiro dispositivo a regulamentar a liberdade de reunião, um exemplo disso é a Lei Estadual $n^{\circ}$ 6.528, de 11 de setembro de 2013, do Rio de Janeiro ${ }^{15}$. Estas normas resultaram dos inúmeros protestos que ocorrem em todo país todo ano. Esta realidade trouxe à tona questões sobre as limitações do direito à manifestação. Dessa forma, apresentaremos a seguir a análise dos limites da liberdade de reunião com base na bibliografia constitucional brasileira.

Para que seja possível o estudo dos limites dessa liberdade, é necessário conceituar a reunião. Esta não deve ser confundida com aglomerações de pessoas. A reunião constitucionalmente protegida não é caracterizada somente pelo o encontro de várias pessoas, estas devem estar naquele local com um objetivo em comum. Portanto, haverá uma relação entre os manifestantes ${ }^{16}$.

\subsection{PACÍFICA E SEM ARMAS}

O primeiro limite suscitado dessa liberdade tem relação com a forma da realização das manifestações. O inciso XVI do artigo $5^{\circ}$ da Constituição Federal brasileira prevê que "todos podem reunir-se pacificamente, sem armas".

A reunião pacífica pode ser conceituada como aquela não beligerante e não armada. Portanto, a manifestação que não é protegida constitucionalmente é aquela que apresenta dois elementos: intencional (subjetivo) e de fato (objetivo). Estes dois elementos juntos devem caracterizar um grave potencial de dano. Dessa forma, a existência de somente um dos elementos não basta para considerar a manifestação como não pacífica. A simples intenção de lesar algum bem jurídico, sem que se portem objetos que sejam suficientes para isso, bem como o porte de um objeto que possui um potencial lesivo, mas que não possua a

Estados Americanos, sob a justificativa que este dispositivo respalda confrontos entre os policias e manifestantes. Link: https://g1.globo.com/sp/sao-paulo/noticia/2020/01/23/bancada-ativista-na-alespdenuncia-na-oea-acao-da-pm-e-decreto-de-doria-que-regulamenta-protestos.ghtml

${ }^{15}$ Esta Lei foi objeto de uma ADI Estadual, que foi considerada constitucional pelo Tribunal de Justiça do Rio de Janeiro. Neste momento, o processo encontra-se no Supremo Tribunal Federal, em que foi declarada repercussão geral da matéria (Tema 912 - Possibilidade de lei proibir o uso de máscaras em manifestações públicas), cujo relator é o Ministro Roberto Barroso.

16 SOUSA, 2012, p.3. 
intenção beligerante não é suficiente para que seja considerada uma reunião não pacífica ${ }^{17}$. Conforme já exposto, a doutrina alemã preceitua que não é possível a interpretação muito ampla do termo "pacífico", pois isso seria a negação deste direito, uma vez que excluiria qualquer possibilidade de lesão.

Nesse sentido, existe o questionamento quanto o conceito de "arma". Segundo o jurista Guilherme de Souza Nucci arma ${ }^{18}$ :

é o instrumento utilizado para defesa ou ataque. Denominase arma própria, a que é destinada, primordialmente, para ataque ou defesa (ex.: armas de fogo, punhal, espada, lança etc.). Logicamente, muitas outras coisas podem ser usadas como meios de defesa ou de ataque. Nesse caso, são as chamadas armas impróprias (ex.: uma cadeira atirada contra o agressor; um martelo utilizado para matar; uma ferramenta pontiaguda servindo para intimidar).

Diante disso, pode-se afirmar que "arma" não é necessariamente "arma de fogo". A partir do conceito explicitado, surgem questões, como por exemplo, se a reunião proibida é aquela em que todos os participantes portam armas. Nesta questão, existem três situações a serem analisadas. Na primeira, todos os participantes da manifestação portam armas. Na segunda, uma pequena parte portam armas. Na terceira e última situação, pequena parte tem o porte, no entanto a grande maioria dos participantes sabe e apoia essa conduta. As duas primeiras situações são mais fáceis de serem resolvidas: a primeira é proibida e a segunda é permitida. Porém, a terceira situação é mais complexa. Para solucioná-la será necessária a análise conjunta do elemento subjetivo. Neste caso, se os outros participantes da manifestação sabem do porte das armas e sabem do objetivo de lesionar bens jurídicos de terceiros, esta reunião deverá ser proibida. Por outro lado, se esses manifestantes sabem do porte de armas, mas não sabem da intenção de lesionar, a reunião é protegida constitucionalmente ${ }^{19}$.

Assim sendo, a partir do que foi exposto é possível afirmar que para a caracterização de reunião proibida é necessária a análise da intenção e a beligerância dos participantes da manifestação. Caso uma parte dos manifestantes tenha condutas agressivas, não é necessária a dissolução de toda a reunião. É possível somente impedir que esses participantes tenham tais condutas.

\footnotetext{
${ }^{17}$ LAURENTIIS, 2017, p. 585.

${ }^{18}$ NUCCI, 2010, p. 761.

${ }^{19}$ DIAS e LAURENTIIS, 2014, p.649-669.
} 


\subsection{USO DE MÁSCARAS}

Dando continuidade ao desenvolvimento do tema, passaremos para o estudo do ponto central do presente artigo: a proibição do uso de máscaras ou de qualquer paramento que não permita a identificação em manifestações. Para que uma manifestação seja proibida por conta do uso de máscaras pelos participantes, é necessário realizar a análise da intenção beligerante desses manifestantes, assim como deve ser feito com o porte de armas.

A pandemia do coronavírus evidenciou que o uso de máscaras nem sempre tem o objetivo de esconder a identidade do indivíduo para cometer atos delitivos. A máscara pode ser usada como proteção de uma doença, bem como pode ser usada como uma forma de manifestação cultural ou religiosa, como por exemplo, o uso de Burcas. Dessa forma, a máscara pode ser usada como uma maneira de expressão de ideias, de reinvindicações. Além disso, as máscaras podem ser utilizadas como forma de defesa pessoal (máscaras contra gás).

O Decreto 64.074 elaborado pelo Governador do Estado de São Paulo proíbe o uso de máscaras sob a justificativa de que a Constituição Federal de 1988 veda o anonimato quando dispõe sobre a liberdade de manifestação de pensamento ${ }^{20}$. Segundo o jurista alemão, Robert Alexy, a restrição de um direito fundamental só poderá ser feita quando há fundamento constitucional ${ }^{21}$. Caso fosse a intenção do constituinte de proibir o uso de máscaras em manifestações, ele o teria feito no inciso próprio da liberdade de reunião, não cabe ao legislador ordinário impor um limite a um direito fundamental que não possui respaldo constitucional.

A tentativa de justificar a proibição do uso de máscaras através da vedação do anonimato é inválida, uma vez que não existe reunião anônima, os participantes querem visibilidade de suas ideias. Por isso saem às ruas para se manifestar. Caso contrário, ficariam em casa. Além disso, caso o policial aferir a necessidade de identificação do participante, basta que este apresente sua identificação civil através de documento. Na falta deste, poderá ser feita a identificação penal. Nessas situações, a identificação seria feita independentemente

\footnotetext{
${ }^{20}$ Art. $5^{\circ}$ Todos são iguais perante a lei, sem distinção de qualquer natureza, garantindo-se aos brasileiros e aos estrangeiros residentes no País a inviolabilidade do direito à vida, à liberdade, à igualdade, à segurança e à propriedade, nos termos seguintes: IV - é livre a manifestação do pensamento, sendo vedado o anonimato;

${ }^{21}$ Alexy, 1993, p. 277. Neste ponto, o professor de direito constitucional da Faculdade de Direito da USP, Roger Leal, afirma em seu texto "A propriedade como direito fundamental" que as limitações de direito fundamental podem ser diretamente fixadas pelo texto constitucional ou impostas por lei infraconstitucional autorizada expressa ou tacitamente pela Constituição Federal. No caso apresentado, não existe restrição expressa ou tácita à liberdade de reunião na Carta Magna quanto ao uso de máscaras durante as manifestações.
} 
de máscaras. Nos casos em que os manifestantes cobrem os rostos para não aparecerem nos veículos de comunicação, mas mesmo assim desejam participar da reunião, eles estarão exercendo o seu direito de imagem e personalidade ${ }^{22}$.

A única hipótese em que é proibido o uso de máscaras em manifestação é quando a vestimenta tem caráter paramilitar. Nos casos em que as máscaras são usadas com a intenção de vandalismo, não é permitido o uso delas. Ou seja, é necessária a análise da intenção beligerante do participante.

Portanto, esta restrição imposta pelo Governador do estado de São Paulo através do Decreto 64.074 não possui respaldo constitucional, uma vez que somente a Constituição Federal poderá impor um limite a um direito fundamental como a liberdade de reunião.

Este Decreto teve o objetivo de regulamentar a Lei 15.556 de 2014. Esta lei foi elaborada em um momento em que havia grande movimentação social no país e a proibição do uso de máscaras foi uma medida tomada pelo Estado, para que fossem freadas manifestações. O tema está para ser discutido no Supremo Tribunal Federal, que teve sua repercussão geral reconhecida.

Atualmente, a aplicação deste Decreto não tem sido feita por conta da elaboração de outro Decreto pelo Governador do estado de São Paulo durante a pandemia do Coronavírus, em que obrigou o uso de máscaras em todo o território paulista ${ }^{23}$.

Dessa forma, existe um conflito entre as duas normas. Uma que proíbe o uso de máscaras durante as manifestações e outra que obriga o uso de máscaras em todo o território paulista.

\footnotetext{
${ }^{22}$ DIAS. LAURENTIIS, 2014, p.665.

${ }^{23}$ Decreto no $63.959 / 2020$ Artigo $1^{\circ}$ - Enquanto perdurar a medida de quarentena instituída pelo Decreto ${ }^{\circ}$ 64.881, de 22 de março de 2020, fica determinado, em complemento ao disposto no Decreto $\mathrm{n}^{\circ}$ 64.956, de 29 de abril de 2020, o uso obrigatório de máscaras de proteção facial, preferencialmente de uso não profissional:

I - nos espaços de acesso aberto ao público, incluídos os bens de uso comum da população;

II - no interior de:

a) estabelecimentos que executem atividades essenciais, aos quais alude o $\S 1^{\circ}$ do artigo $2^{\circ}$ do Decreto $n^{\circ} 64.881$, de 22 de março de 2020, por consumidores, fornecedores, clientes, empregados e colaboradores;

b) em repartições públicas estaduais, pela população, por agentes públicos, prestadores de serviço e particulares. $\S 1^{\circ}$ - O descumprimento do disposto neste artigo sujeitará o infrator, conforme o caso, às penas previstas nos incisos I, III e IX do artigo 112 da Lei no 10.083, de 23 de setembro de 1998 - Código Sanitário do Estado, sem prejuízo:

1. na hipótese da alínea "a" do inciso II, do disposto na Lei federal n ${ }^{\circ} 8.078$, de 11 de setembro de 1990 - Código de Defesa do Consumidor;

2. na hipótese da alínea "b" do inciso II, do disposto na Lei no 10.261, de 28 de outubro de 1968;

3. em todas as hipóteses, do disposto nos artigos 268 e 330 do Código Penal.

$\S 2^{\circ}$ - O uso de máscaras de proteção facial constitui condição de ingresso e frequência eventual ou permanente, nos recintos a que alude o inciso II deste artigo.
} 
A situação atual evidencia na prática que o uso de máscaras não traz prejuízos à realização de manifestações, conforme o que preceitua a Constituição Federal. Como prova disso, são as manifestações pacíficas, não armadas e organizadas em local público aberto ao público, realizadas na cidade de São Paulo durante a pandemia do Coronavírus, em que todos os participantes vestiam máscaras para proteção do vírus. ${ }^{24}$

\subsection{LOCAL DA REUNIÃO}

Por fim, a última restrição à liberdade de reunião abordada é quanto ao local em que as manifestações podem ser realizadas. A Constituição Federal determina que sejam autorizadas as reuniões organizadas em locais abertos ao público. Dessa forma, não há uma distinção se a propriedade é público ou privada. Se fosse só em propriedades públicas estaria escrito "locais abertos e públicos". Diante disso, existem quatro hipóteses a serem consideradas: na primeira a manifestação é realizada em local de propriedade pública e aberta ao público, como praças; a segunda a reunião é organizada em local de propriedade da Administração Pública, porém é fechada ao público, como por exemplo, o gabinete do Reitor de uma universidade pública; a terceira hipótese se refere às manifestações que ocorrem em local de propriedade privada, pertence a particulares, no entanto é aberto ao público, como os shoppings centers; finalmente, na quarta hipótese a reunião é realizada em uma propriedade privada e fechada ao público ${ }^{25}$.

As duas primeiras situações envolvem a legislação administrativa, pois são bens públicos de uso comum da sociedade. Dessa forma, naqueles lugares da Administração Pública que não têm restrição de acesso, é permitida a realização de manifestações. Por outro lado, os locais que são bens públicos, mas têm acesso restrito para a entrada, não será permitida a organização de reuniões nesses lugares. Vale ressaltar que, as manifestações realizadas na sede do Poder Legislativo são protegidas apesar de ter acesso restrito ao público. Isso se deve ao fato de esse local ser destinado ao debate público de ideias, por isso não é possível proibir essas reuniões.

\footnotetext{
${ }^{24}$ MTST faz nova manifestação contra despejos durante a pandemia do coronavírus em SP. Link: https://g1.globo.com/sp/sao-paulo/noticia/2020/08/13/mtst-faz-nova-manifestacao-contra-despejos-durante-apandemia-do-coronavirus-em-sao-paulo.ghtml

${ }^{25}$ LAURENTIIS, 2017, p. 584.
} 
As outras duas hipóteses envolvem a propriedade privada e geram maiores discussões. O direito brasileiro não possui definição do bem particular aberto ao público. Logo, usaremos os direitos à liberdade de reunião e à inviolabilidade de domicílio para que seja feita a distinção. Nesse sentido, a jurisprudência brasileira tem uma interpretação ampliativa quanto ao direito da inviolabilidade de domicílio: o local de trabalho também é protegido por este direito. Portanto, somente em situações específicas do local de trabalho em que serão permitidas reuniões em locais privados. Um exemplo disso é o movimento grevista que ocupa o espaço da agência bancária. Neste caso, haverá uma colisão entre dois direitos fundamentais: o da liberdade de reunião e o da inviolabilidade de domicílio. Para resolver este conflito é possível aplicar a técnica da proporcionalidade já explicitada anteriormente neste trabalho ${ }^{26}$.

Diante disso, é possível afirmar que as manifestações realizadas em propriedades privadas fechada ao público não são protegidas constitucionalmente. Neste caso, o direito à inviolabilidade domiciliar será aplicado à situação concreta. Já nos casos das reuniões realizadas em locais privados aberto ao público, como os shoppings center, estão protegidas, pois nestes locais se pressupõe a circulação do público, em que haverá convivência de pessoas com ideias e interesses diversos que são essenciais para a atividade do centro de compras. Dessa forma, não é possível que o titular da referida propriedade somente permita a entrada de pessoas com determinadas ideias, já que viver em uma democracia é viver com ideias que nem sempre concordamos.

\section{CONCLUSÃO}

Nos dois casos apresentados pelo texto foi possível observar e analisar os limites da liberdade de reunião suscitados pelo direito constitucional brasileiro e alemão. Em alguns pontos os casos se aproximam como, por exemplo, no ponto em que se destaca que ambos protegem as manifestações pacíficas. Por outro lado, em outros pontos, eles se distanciam como, por exemplo, quanto à titularidade do direito, que no direito alemão só é garantido para os alemães e no direito brasileiro é garantido para todos, sem distinções.

O tema do uso de máscaras foi abordado nos dois casos. Para o Tribunal Constitucional Alemão a realização de manifestações durante a pandemia do Coronavírus é

${ }^{26}$ LAURENTIIS, 2017, p. 584. 
protegida pela Lei Fundamental alemã, desde que os participantes respeitem as medidas sanitárias adotadas pelo estado de Hesse, ou seja, usem máscaras e mantenham entre si o distanciamento mínimo de 1 metro e meio. Por outro lado, a legislação do estado de São Paulo proíbe o uso de máscaras em manifestações, sob a justificativa da vedação constitucional do anonimato. Porém, em meio à pandemia do mesmo vírus, foi decretado o uso obrigatório de máscaras, causando conflitos entre as normas elaboradas pelo Governador.

Desse modo, foi possível concluir, a partir das análises de textos científicos, que a restrição imposta pelo Governo do estado de São Paulo é inconstitucional, não sendo possível criar uma restrição a um direito fundamental que não esteja previamente prevista na Constituição Federal.

Quanto aos limites da reunião pacífica e do porte de armas, foi evidenciado que é necessário analisar em conjunto os elementos subjetivos e objetivos, ou seja, a intenção do participante, bem como a situação de fato.

Nesse sentido, quanto ao uso de máscaras durante as manifestações foi possível observar que a Constituição Federal brasileira não prevê esta limitação, portanto, não é possível criá-la através de um Decreto. Além disso, foi concluído que o uso de máscaras não prejudica a realização desta de forma pacífica.

Por fim, quanto ao local em que as manifestações podem ser organizadas, foi constatado que é possível que uma reunião seja realizada em uma propriedade privada aberta ao público. Isso ocorre, pois o texto constitucional preceitua que as manifestações podem acontecer em "locais abertos ao público", de forma que estão incluídas as propriedades privadas e públicas, desde que abertas para o público.

\section{REFERÊNCIAS BIBLIOGRÁFICAS}

CARDOSO, Diego Brito. Colisão de direitos fundamentais, ponderação e proporcionalidade na visão de Robert Alexy, Revista Constituição e Garantia de Direitos, v. 9, n. 1, p. 137 - 155, 5 out. 2016. 
DIAS, Roberto; LAURENTIIS, Lucas Catib de. Liberdade de reunião e democracia: reflexões a partir das experiências brasileiras e alemãs, RBEC, n. 30, Belo Horizonte (2014): 649-669.

HOFFMANN-RIEM, Neuere Rechtsprechung des BVerfG zur Vesammlungsfreiheit. NVwZ (2003): 257-265.

KNIESEL, Michael; POSCHER, Ralf. Die Entwicklung des Versammlungsrecht 2000 bis 2003, NUW (2004): 422-429.

LAURENTIIS, Lucas Catib de. Manifestações públicas e privadas: ideias, ações, expressões e o caso "rolezinho", Quaestio Juris, vol.10, n.02, (2017): 580-592.

MARTINS, Leonardo. Liberdade e Estado constitucional: A Complexa relação a partir da teoria liberal direitos fundamentais, São Paulo: RT, 2012.

MICHAEL, Lothar; MORLOK, Martin. Grundrechte. 5. ed. Baden-Baden: Nomos, 2016.

NUCCI, Guilherme de Souza. Código penal anotado, São Paulo: Revista dos Tribunais, 2008.

POSCHER, Ralf. Grundrechte als Abwehrrechte: reflexive Regelung rechtlich geordneter Freiheit, Tübingen: Mohr-Siebeck, 2003.

SACHS, Michael. Verfassungrecht II: Grundrechte, Heidelberg: Springer Verlag, 2003. SOUSA, António Francisco de. Liberdade de Reunião e de Manifestação no Estado de Direito. Direitos Fundamentais e Justiça, ano 6, n. 21, p. 27-38, out./dez. 2012. 